\title{
Using Pretreatment of Carbon Monoxide Combined with Chlorine Dioxide and Lactic Acid to Maintain Quality of Vacuum-Packaged Fresh Beef
}

\author{
Fei Lyu $(\mathbb{D}$, Yuliang Zhao, Kejing Shen, Xuxia Zhou, Jianyou Zhang $\mathbb{D}$, and Yuting Ding \\ Department of Food Science and Technology, Zhejiang University of Technology, Hangzhou 310014, China \\ Correspondence should be addressed to Jianyou Zhang; zhjianyou@zjut.edu.cn and Yuting Ding; dingyt@zjut.edu.cn
}

Received 8 September 2017; Revised 23 December 2017; Accepted 29 January 2018; Published 15 March 2018

Academic Editor: Flora V. Romeo

Copyright (C) 2018 Fei Lyu et al. This is an open access article distributed under the Creative Commons Attribution License, which permits unrestricted use, distribution, and reproduction in any medium, provided the original work is properly cited.

\begin{abstract}
Due to microbial growth, beef easily gets corrupt in retail conditions, and the color and quality of the meat will be deteriorated. Therefore, hurdle technology, namely, pretreatment of carbon monoxide (CO), chlorine dioxide, and lactic acid, is used for vacuumpackaged beef to decontaminate beef and increase its quality stability. Beef was pretreated with $100 \% \mathrm{CO}(\mathrm{C} 1), 100 \% \mathrm{CO}$ and $50 \mathrm{mg} / \mathrm{L}$ chlorine dioxide (C2), and 100\% CO and $50 \mathrm{mg} / \mathrm{L}$ chlorine dioxide and $30 \mathrm{~g} / \mathrm{L}$ lactic acid (C3). The untreated samples were used as control (CK). During storage, the $a^{*}$ color parameters of $\mathrm{C} 1, \mathrm{C} 2$, and $\mathrm{C} 3$ were significantly higher than that of CK, indicating $\mathrm{CO}$ pretreatment is a good way to maintain color appearance of beef, and chlorine dioxide and lactic acid did not affect the colorprotecting role of $\mathrm{CO}$ on beef. $\mathrm{C} 3$ showed the strongest antimicrobial activity with the lowest total viable counts, followed by $\mathrm{C} 2, \mathrm{C}$, and CK. Samples in C3 also showed the lowest total volatile basic nitrogen, $\mathrm{pH}$, thiobarbituric acid reactive substance, and metmyoglobin during the mid-late storage. Moreover, C3 can keep beef with higher unsaturated fatty acids. In conclusion, $\mathrm{CO}$ pretreatment combined with chlorine dioxide and lactic acid displayed efficient antimicrobial and color-stability activity for vacuum-packaged beef. It would be a potential way to use pretreatment of $\mathrm{CO}$ combined with chlorine dioxide and lactic acid to maintain the quality of vacuum-packaged beef.
\end{abstract}

\section{Introduction}

Microbial growth is the main reason of fresh meat spoilage, and the increasing microorganisms will modify the color and quality of the meat [1]. Therefore, many antimicrobial techniques have been promoted to preserve fresh meats. Antimicrobial is the basis of the decontamination for meat which is useful in extending shelf life of meats by reducing or eliminating survival of pathogenic and spoilage bacteria and increasing overall quality of food products. Chlorine dioxide $\left(\mathrm{ClO}_{2}\right)$ has been used as a powerful antimicrobial to reduce microorganisms [2]. Lactic acid is a generally regarded as decontaminating agent for reduction or elimination of spoilage and pathogenic microorganisms from beef [3]. Rodríguez-Melcón et al. [4] found that lactic acid not only improved microbial quality, but also enhanced sensory properties and shelf life of beef. Lactic acid and chlorine dioxide were reported to have broad antimicrobial effects with lower toxicities and more stable forms, making them promising candidates for decontamination [5-7]. In order to inhibit the growth of microorganisms of fresh meats, vacuum packaging is also used in food industry. However, vacuum-packaged fresh meat is unsuitable for the retail market because the lack of oxygen in the package causes a change of meat color from red to purple due to the conversion of oxymyoglobin to deoxymyoglobin [8]. Color is the most frequent criterion for judging shelf life and acceptability of fresh meats and it determines the consumes' decision of whether or not to purchase [9]. Due to the formation of carboxymyoglobin between carbon monoxide (CO) and myoglobin [10], $\mathrm{CO}$ is very effective in maintaining red color for fresh meats [1116]. The use of $\mathrm{CO}$ as a packaging gas has many benefits including increased color stability, shelf-life extension due to microbial inhibition properties, enhanced flavor, reduced protein oxidation and lipid oxidation, improved tenderness, and prevention of premature browning. In the USA, low 
concentration of CO $(0.4 \%)$ is generally recognized as safe and is approved by the FDA and $\mathrm{CO}$ is permitted as a primary packaging gas in case-ready packaging systems. Similarly, Canada also allows the application of $0.4 \% \mathrm{CO}$ as a secondary packaging gas [16].

Although $\mathrm{CO}$ and vacuum packaging have been used to maintain the fresh meat quality; the antimicrobial effects of them are limited. Van Rooyen et al. [16] reported that the combination of $\mathrm{CO}$ pretreatment and vacuum packaging can improve the color stability of beef, but there is adverse effect on the antimicrobial status; the aerobic psychrophiles and anaerobic psychrophiles come up to $7 \mathrm{log} \mathrm{CFU} / \mathrm{g}$. Therefore, it is necessary to study useful methods to maintain quality of vacuum-packaged beef. Nowadays, hurdle technique, namely, using multiple antimicrobial treatments to inhibit microorganisms in meats, has been shown to be more effective than single intervention. Based on the color unacceptability of vacuum-packaged fresh meats and the demands of inhibiting microbial growth to maintain quality of fresh meat, we proposed using CO pretreatment, following antimicrobial processing with chlorine dioxide combined with lactic acid to maintain quality of vacuum-packaged fresh beef. To the best of our knowledge, limited information is available on the combined effects of $\mathrm{CO}$, chlorine dioxide, and lactic acid on microbiological and physiochemical changes of vacuum-packaged fresh beef. Therefore the objective of this research was to determine the effect of combined pretreatment of $\mathrm{CO}$, chlorine dioxide, and lactic acid on the qualities of beef by analyzing microbiological and physiochemical characteristics of beefsteaks.

\section{Materials and Methods}

2.1. Raw Materials. A total of 8 Luxi $\times$ Simmental steers (18-24 months old, $286-323 \mathrm{~kg}$ ) were selected randomly from a local farm and slaughtered on a commercial abattoir. The longissimus lumborum and psoas major of the tenderloin were removed from both sides of the carcasses after $48 \mathrm{~h}$ postmortem, with all visible fat trimmed off, and cut into beefsteaks about $50 \mathrm{~g}$ with $2 \mathrm{~cm}$ thickness.

2.2. Sample Preparation. Beefsteaks were divided into four groups randomly. The first group of steaks were untreated and used as control (CK), the second group of steaks were pretreated with $100 \% \mathrm{CO}$ for $1.5 \mathrm{~h}(\mathrm{C1})$, the third group was pretreated with the same $\mathrm{CO}$ and then immersed in $50 \mathrm{mg} / \mathrm{L}$ chlorine dioxide for $10 \mathrm{~min}$ (C2), and the last group of steaks were pretreated the same $\mathrm{CO}$ and chlorine dioxide and then spayed with $30 \mathrm{~g} / \mathrm{L}$ lactic acid (C3). All samples were vacuumpackaged and stored at $4 \pm 1^{\circ} \mathrm{C}$ for up to 28 days. Microbial and physicochemical characteristics of beefsteaks were analyzed on $0,7,14,21$, and 28 days.

2.3. Color Measurement. Variability of physical color parameters $\left(a^{*}\right)$ at the time of storage was measured using a colorimeter (Hunter Associates Laboratory Inc., Reston, West Virginia, USA). Samples were read using illuminant A/10 observer and evaluated for $\operatorname{CIE}\left(a^{*}\right)$ color values. This spectrum includes $a^{*}$ (red/green) value as a measure of the red (positive values) and green (negative values) colors of the sample [17]. The colorimeter was standardized using a white tile and a black tile and a working standard made by Hunter Lab manufacturer. The color values were the mean of five measurements per steak, and three steaks were used per pretreatment at each sampling time.

2.4. Microbial Analysis. Total viable counts (TVCs) were detected according to the China National Food Safety Standard methods (GB 4789.2-2010) and Lyu et al. (2016). Meat was minced under sterile condition, and 5-gram minced meats were transferred aseptically into individual stomacher bags (Seward Medical, UK) containing $45 \mathrm{~mL}$ of sterile normal saline $(0.9 \%)$ and homogenized in a stomacher (Lab Blender 400, Seward Medical, UK) for $2 \mathrm{~min}$. For each sample, appropriate serial decimal dilutions were prepared in sterile normal saline $(0.9 \%)$. The amount of $0.1 \mathrm{~mL}$ of these serial dilutions of beef homogenates was spread on the surface of dry media. TVCs were determined using Plate Count Agar after incubation for $48 \mathrm{~h}$ at $37^{\circ} \mathrm{C}$. Microbial counts were expressed with logarithms of the number of colony forming units per gram $(\log 10 \mathrm{CFU} / \mathrm{g})$. The TVC values were the mean of three steaks per treatment at each sampling time.

2.5. PH Measurement. Briefly $5 \mathrm{~g}$ minced beef was homogenized with $45 \mathrm{~mL}$ deionized water using a blender (Lab Blender 400, Seward Medical, UK) at 6,000 rpm for $2 \times$ $15 \mathrm{~s}$, with a $5 \mathrm{~s}$ break. The $\mathrm{pH}$ value was measured with a Microprocessor $\mathrm{pH}$ meter (Mettler-Toledo $\mathrm{GmbH}, 8603$, Schwerzenbach, Switzerland). The $\mathrm{pH}$ values were the mean of three steaks at each sampling time.

2.6. Total Volatile Basic Nitrogen Determination. Total volatile basic nitrogen (TVB-N) was determined according to the China National Food Safety Standard methods, method for analysis of hygienic standard of meat and meat products (GB/T 5009.44-2003), and Lyu et al. (2016). Briefly, $5 \mathrm{~g}$ of minced beef meat was mixed with $45 \mathrm{~mL}$ of perchloric acid $(1.2 \mathrm{M})$ and centrifuged at $8000 \mathrm{rpm}$ for $10 \mathrm{~min}$, and the homogenate was filtered through the filter paper. $5 \mathrm{~mL}$ of filtrate was made alkaline by adding $5 \mathrm{~mL}$ of $20 \% \mathrm{NaOH}$. Steam distillation was performed using Kjeldahl distillation unit (Shanghai Jianqiang Glass Co., China) for $5 \mathrm{~min}$. The distillate was absorbed by $10 \mathrm{~mL}$ of $20 \%$ boric acid and then titrated with $0.01 \mathrm{~mol} / \mathrm{L} \mathrm{HCl}$. Total volatile basic nitrogen (TVB-N) content was calculated and expressed with a unit of $\mathrm{mg} / 100 \mathrm{~g}$. The TVB-N values were the mean of three steaks per pretreatment at each sampling time.

2.7. Metmyoglobin Determination. Metmyoglobin (met-Mb) was extracted following the modified method described by Stewart et al. [18]. Briefly, $5 \mathrm{~g}$ minced meat was homogenized in $45 \mathrm{~mL}$ of $0.04 \mathrm{M}$ phosphate buffer, $\mathrm{pH} 6.8$ [19]. Homogenates were held, on ice, for $30 \mathrm{~min}$ to allow complete pigment extraction before centrifugation $(10,000 \times \mathrm{g})$ for $10 \mathrm{~min}$ at $4^{\circ} \mathrm{C}$. The met-Mb (\% of total) was calculated based on absorbance of clarified extract at 525, 572, and 
$700 \mathrm{~nm}[20,21]$ using a Model UV-1800 UV-VIS recording spectrophotometer (Shimadzu, Instruments of Mfg. Co. Ltd., Suzhou, China). The met-Mb values were the mean of three steaks per pretreatment at each sampling time. The met- $\mathrm{Mb}$ content was calculated using the following formula:

$$
\operatorname{Met}-\operatorname{Mb}(\%)=\left\{1.395-\left[\frac{(A 572-A 700)}{(A 525-A 700)}\right]\right\} \times 100 .
$$

\subsection{Thiobarbituric Acid Reactive Substance Determination.} Thiobarbituric acid reactive substance (TBARS) assays were performed on the beefsteaks using the procedures described by Luqué et al. [22]. Briefly, $5 \mathrm{~g}$ minced beef meat was homogenized for $1 \mathrm{~min}$ at approximately $12,000 \mathrm{rpm}$ in $30 \mathrm{~mL}$ of trichloroacetic acid (TCA) solution (7.5\% TCA, 0.1\% PG, and $0.1 \%$ ethylenediaminetetraacetic acid). The mixture was filtrated through Whatman Grade-2 filter paper (SigmaAldrich, USA) and $5 \mathrm{~mL}$ of $20 \mathrm{mM}$ thiobarbituric acid was added to $5 \mathrm{~mL}$ of the filtrate. The solution was then incubated for $40 \mathrm{~min}$ at $100^{\circ} \mathrm{C}$ in closed test tubes. The absorbance of the supernatant was measured spectrophotometrically (UV-1800, Shimadzu, Instruments of Mfg. Co. Ltd., Suzhou, China) at $532 \mathrm{~nm}$ against a blank that contained all the reagents minus the meat [23-25]. A standard curve was prepared using 1,1,3,3-tetramethoxypropane at a concentration ranging from 0 to $10 \mathrm{ppm}$, and the amounts of TBARS were expressed as $\mathrm{mg}$ of MDA/ $\mathrm{kg}$ sample. The TBARS values were the mean of three steaks per pretreatment at each sampling time.

2.9. Fatty Acid Profile Determination. Total lipids of beef were extracted by the method of Folch et al. [26]; then the fatty acid was methylated with $14 \%$ boron trifluoride methanol complex in methanolic solution [27]. Fatty acid methyl ester (FAME) was determined by gas chromatograph (Agilent 6890 GC, Santa Clara, CA, USA) with a split/splitless injector, a flame-ionization detector, and a $30 \mathrm{~m}$ fused silica capillary column $(30 \mathrm{~m} \times 0.32 \mathrm{~mm} \times 0.25 \mu \mathrm{m}$ film thickness $)$ used, with helium as the carrier gas (flow rate $=1 \mathrm{~mL} / \mathrm{min}$ ). The initial temperature in the oven was $100^{\circ} \mathrm{C}$ and it reached $220^{\circ} \mathrm{C}$ with increasing rate of $5^{\circ} \mathrm{C} / \mathrm{min}$; then it reached $230^{\circ} \mathrm{C}$ with increasing rate of $1^{\circ} \mathrm{C} / \mathrm{min}$. Injector and detector temperatures were at $220^{\circ} \mathrm{C}$ and $250^{\circ} \mathrm{C}$, respectively. The fatty acids were identified by comparison of their FAME retention times with sigma reference standards (Supelco ${ }^{\mathrm{TM}} 37$ Component FAME mix, Sigma, St. Louis, MO, USA). The individual fatty acid level was expressed as the percentages of total fatty acid content.

2.10. Statistical Analysis. A completely randomized design experiment was conducted for each test. Data were expressed as mean \pm Standard Error of three replications, used as the storage periods (day 0, 7, 14, 21, and 28) and different groups $(\mathrm{CK}, \mathrm{Cl}, \mathrm{C} 2$, and $\mathrm{C} 3)$, and then analyzed by one-way analysis of variance (ANOVA) and least significant difference (LSD) using SPSS statistical package (22.0). Significant difference was considered at $P<0.05$.

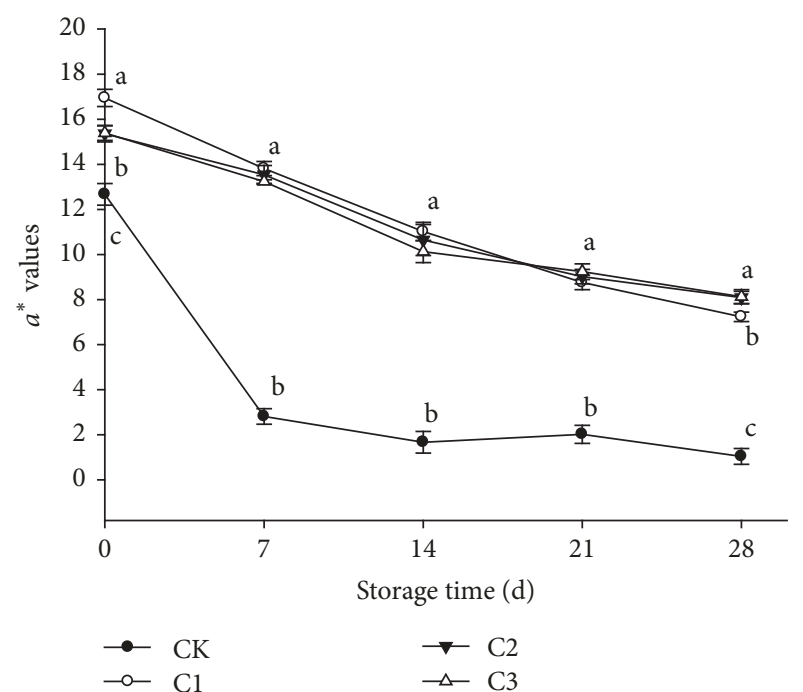

FIGURE 1: Changes in $a^{*}$ values of beefsteaks with different treatments during storage. CK, the group of beefsteaks without pretreatments; $\mathrm{Cl}$, the group of beefsteaks pretreated with $100 \% \mathrm{CO}$ for $1.5 \mathrm{~h}$; C2, group of beefsteaks pretreated with $100 \% \mathrm{CO}$ for $1.5 \mathrm{~h}$ and soaked in $50 \mathrm{mg} / \mathrm{L} \mathrm{ClO}_{2} ; \mathrm{C} 3$, group of beefsteaks pretreated with $100 \% \mathrm{CO}$ for $1.5 \mathrm{~h}$ and soaked in $50 \mathrm{mg} / \mathrm{L} \mathrm{ClO}$, for $10 \mathrm{~min}$ and sprayed with $30 \mathrm{~g} / \mathrm{L}$ lactic acid. Data were represented with mean values \pm Standard Error; sometimes the bars were too small to see. Different letters mean significant difference of samples with different treatments on the same storage days $(P<0.05)$. Three separate steaks of each treatment were measured; three repetitions were performed for each treatment. $n=9$.

\section{Results and Discussion}

3.1. Color Analysis. Changes of $a^{*}$ values of beefsteaks during vacuum storage at $4^{\circ} \mathrm{C}$ are presented in Figure 1. Samples of $\mathrm{C} 1, \mathrm{C} 2$, and $\mathrm{C} 3$ had higher redness than $\mathrm{CK}$ during the whole storage. It indicated that $\mathrm{CO}$ exposure to beef for $1.5 \mathrm{~h}$ was sufficient to enhance the color of meats. The CO pretreatment time was shorter than researches of Van Rooyen et al. [16] who reported that beef pretreated with $\mathrm{CO}$ for $5 \mathrm{~h}$ had desirable color. C2 and C3 made beefs have lower $a^{*}$ value $(P<0.05)$ than $\mathrm{C} 1$ on day 0 , and $\mathrm{C} 2$ and $\mathrm{C} 3$ did not show significant differences $(P>0.05)$ to each other. The reason why $a^{*}$ value decreased on day 0 might be due to the oxidation activity of $\mathrm{ClO}_{2}$. Similar result was reported by Stivarius et al. [2] who found that ground beef placed into a meat tumbler with $200 \mathrm{ppm} \mathrm{ClO}_{2}$ and aerobically tumbled for $3 \mathrm{~min}$ ( $16 \mathrm{rpm}$ ) displayed lower $a^{*}$ values than the untreated samples. It also indicated that sprayed $30 \mathrm{~g} / \mathrm{L}$ lactic acid on beef did not have a negative effect on the color of the $\mathrm{ClO}_{2}$ treated beef. According to the result of Pipek et al. [28], the sprayed lactic acid on meats can cause only subtle color changes and did not have negative influence on the surface appearance. With the extension of storage days, the difference between $\mathrm{C} 1, \mathrm{C} 2$, and $\mathrm{C} 3$ changed; samples of $\mathrm{C} 2$ and $\mathrm{C} 3$ displayed higher $a^{*}$ values than $\mathrm{Cl}$ at every sampling time. This change might be contributed by the antimicrobial activity of $\mathrm{ClO}_{2}$ and lactic acid. Thus, concerning the whole 


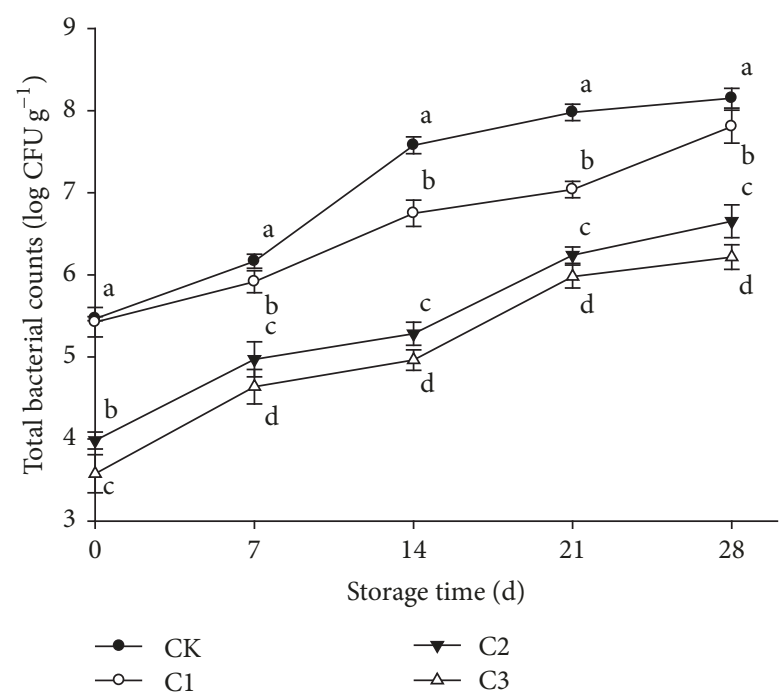

Figure 2: Changes in total bacterial counts of beefsteaks with different treatments during storage. $\mathrm{CK}$, the group of beefsteaks without pretreatments; $\mathrm{Cl}$, the group of beefsteaks pretreated with $100 \%$ CO for $1.5 \mathrm{~h}$; C2, group of beefsteaks pretreated with $100 \%$ CO for $1.5 \mathrm{~h}$ and soaked in $50 \mathrm{mg} / \mathrm{LClO}_{2}$; $\mathrm{C} 3$, group of beefsteaks pretreated with $100 \% \mathrm{CO}$ for $1.5 \mathrm{~h}$ and soaked in $50 \mathrm{mg} / \mathrm{L} \mathrm{ClO}_{2}$ for $10 \mathrm{~min}$ and sprayed with $30 \mathrm{~g} / \mathrm{L}$ lactic acid. Data were represented with mean values \pm Standard Error; sometimes the bars were too small to see. Different letters mean significant difference of samples with different treatments on the same storage days $(P<0.05)$. Three separate steaks of each treatment were measured; three repetitions were performed for each treatment. $n=9$.

storage, chlorine dioxide and lactic acid do not have negative effect on the color of beef, and they even help CO maintain the color of beef.

3.2. Total Viable Counts Analysis. Microorganism is an important factor influencing the shelf life and quality of meat. Because the deterioration of meat can occur in the existence of microorganisms, estimation of TVC is usually used as the acceptability index for fresh beef $[29,30]$. Changes in TVC of different treatments of vacuum-packaged beef storage are presented in Figure 2. The initial TVC of the beef was between 3.57 and $5.46 \log \mathrm{CFU} / \mathrm{g}$. TVC of all samples increased during the whole storage time. The TVC of CK increased more dramatically than treatment groups. After 28 days of storage, $\mathrm{C} 3$ had lowest TVC in all treatments followed by $\mathrm{C} 2$ and $\mathrm{C} 1$. It indicated that $\mathrm{ClO}_{2}$ could delay the growth of microorganisms, and the combination of $\mathrm{ClO}_{2}$ and lactic acid had an even better antimicrobial activity.

According to Stivarius et al. [2], $\mathrm{ClO}_{2}$ was effective against all bacterial types they evaluated. The residual microorganisms inhibition on meat surfaces imparted by lactic acid had also been observed by Rodríguez-Melcón et al. [4] who reported that beef treated by $4 \%$ lactic acid may not only improve microbial quality, but also enhance shelf life. So far, few researches about the combination of $\mathrm{ClO}_{2}$ and lactic acid applied to meats. But some results found that $\mathrm{ClO}_{2}$ and lactic acid could inhibit the pathogenic bacteria. Smigic et al. [6]

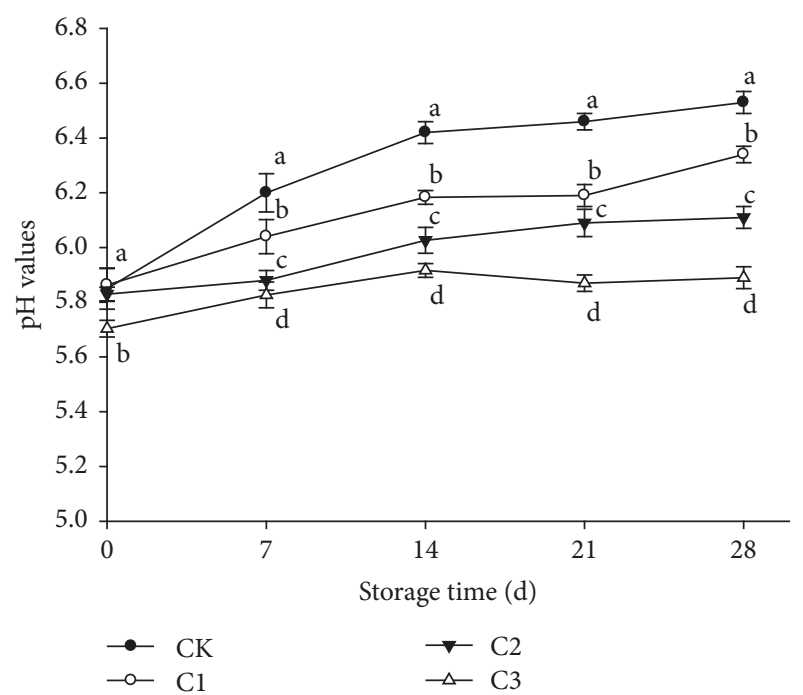

Figure 3: Changes in $\mathrm{pH}$ of beefsteaks with different treatments during storage. CK, the group of beefsteaks without pretreatments; $\mathrm{C} 1$, the group of beefsteaks pretreated with $100 \% \mathrm{CO}$ for $1.5 \mathrm{~h}$; $\mathrm{C} 2$, group of beefsteaks pretreated with $100 \% \mathrm{CO}$ for $1.5 \mathrm{~h}$ and soaked in $50 \mathrm{mg} / \mathrm{L} \mathrm{ClO}_{2}$; C3, group of beefsteaks pretreated with $100 \% \mathrm{CO}$ for $1.5 \mathrm{~h}$ and soaked in $50 \mathrm{mg} / \mathrm{L} \mathrm{ClO}_{2}$ for $10 \mathrm{~min}$ and sprayed with $30 \mathrm{~g} / \mathrm{L}$ lactic acid. Data were represented with mean values \pm Standard Error; sometimes the bars were too small to see. Different letters mean significant difference of samples with different treatments on the same storage days $(P<0.05)$. Three separate steaks of each treatment were measured; three repetitions were performed for each treatment. $n=9$.

found the $\mathrm{ClO}_{2}$ combined with lactic acid treatment had lethal effect on Campylobacter jejuni. Kim et al. [31] stated that $\mathrm{ClO}_{2}$ in organic acid solution has antimicrobial function for the Bacillus cereus spores. Harris et al. [32] found that $4 \%$ lactic acid can have effect of reduction of Salmonella Typhimurium and Escherichia coli O157:H7. All these are in agreement with our result. It means that the combination of $\mathrm{ClO}_{2}$ and lactic acid can help $\mathrm{CO}$ pretreated beef maintain a lower TVC, which might help beef display color stability during the storage. This is in accordance with the change of beef color $a^{*}$ values mentioned above.

3.3. PH Analysis. The $\mathrm{pH}$ changes of beef over 28 days of storage are displayed in Figure 3. The initial values were in a range from 5.70 to 5.86 and similar values were reported in the literatures for beef $[33,34]$. As time went, $\mathrm{pH}$ values of all samples increased due to the activity of the microorganism and enzymes existing in it, which is accompanied by the dissociation of protein constituents and the production of free amino acids leading to formation of ammonia and amines, the alkaline reaction products, and increasing the $\mathrm{pH}$ value of the meat $[35,36]$. Rodrigues et al. [37] also proved that the meat $\mathrm{pH}$ will increase in the shelf life verified as ammonia and amines produced. What is more, Lavieri and Williams [38] observed an increase in meat $\mathrm{pH}$ values packaged with polyvinyl chloride, and the $\mathrm{pH}$ increase was caused by the production of alkaline by-products during the 


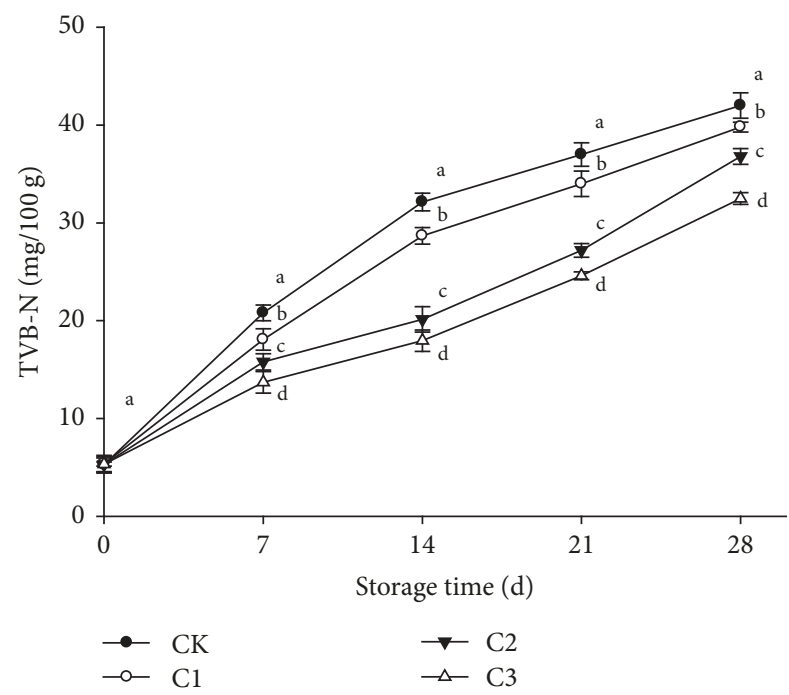

FIgURE 4: Changes in TVB-N values of beefsteaks with different treatments during storage. $\mathrm{CK}$, the group of beefsteaks without pretreatments; $\mathrm{Cl}$, the group of beefsteaks pretreated with $100 \% \mathrm{CO}$ for $1.5 \mathrm{~h}$; C2, group of beefsteaks pretreated with $100 \% \mathrm{CO}$ for $1.5 \mathrm{~h}$ and soaked in $50 \mathrm{mg} / \mathrm{L} \mathrm{ClO}_{2} ; \mathrm{C} 3$, group of beefsteaks pretreated with $100 \% \mathrm{CO}$ for $1.5 \mathrm{~h}$ and soaked in $50 \mathrm{mg} / \mathrm{L} \mathrm{ClO}_{2}$ for $10 \mathrm{~min}$ and sprayed with $30 \mathrm{~g} / \mathrm{L}$ lactic acid. Data were represented with mean values \pm Standard Error; sometimes the bars were too small to see. Different letters mean significant difference of samples with different treatments on the same storage days $(P<0.05)$. Three separate steaks of each treatment were measured; three repetitions were performed for each treatment. $n=9$.

multiplication and stationary phase of microorganisms. At the beginning, the $\mathrm{pH}$ of $\mathrm{C} 3$ was lower $(P<0.05)$ than $\mathrm{CK}$, $\mathrm{C} 1$, and $\mathrm{C} 2$, because of the use of lactic acid. A decrease in $\mathrm{pH}$ values after decontamination with organic acid had been observed by other authors in red meat [39]. The $\mathrm{pH}$ values of samples in $\mathrm{C} 1, \mathrm{C} 2$, and C3 were significantly lower than that of CK during the 28 days of storage, and C3 had lowest $\mathrm{pH}$ value of all groups, followed by $\mathrm{C} 2, \mathrm{C} 1$, and $\mathrm{CK}$. This is in accordance with the changes of TVC.

3.4. TVB-N Analysis. TVB-N is widely used as an indicator of meat spoilage. Figure 4 shows the changes of TVB-N in beef with different treatments during storage. According to Chinese National Standard GB2707-2016, the limit level of TVB-N for livestock products is $15 \mathrm{mg} / 100 \mathrm{~g}$. The initial TVB-N ranged from 5.27 to $5.34 \mathrm{mg} / 100 \mathrm{~g}$ on day 0 , indicating all samples were fresh meats at the beginning. Guo et al. [40] divided livestock products into three levels according to TVB-N contents: $0-15 \mathrm{mg} / 100 \mathrm{~g}$ TVB-N fresh; 15-25 mg/100 g TVB-N, semifresh; and above $25 \mathrm{mg} / 100 \mathrm{~g}$ TVB-N, spoiled. After 7 days of storage, all treatments except C3 had exceeded the limit level of $15 \mathrm{mg} / 100 \mathrm{~g}$. TVB-N of all samples increased obviously, and samples in CK increased most rapidly, followed by $\mathrm{C} 1, \mathrm{C} 2$, and $\mathrm{C} 3$. On day 14 , TVB-N of $\mathrm{CK}$ and $\mathrm{C} 1$ had spoiled limit level of beyond $25 \mathrm{mg} / 100 \mathrm{~g}$. After 21 days of storage, TVB-N of C2 and C3 was still

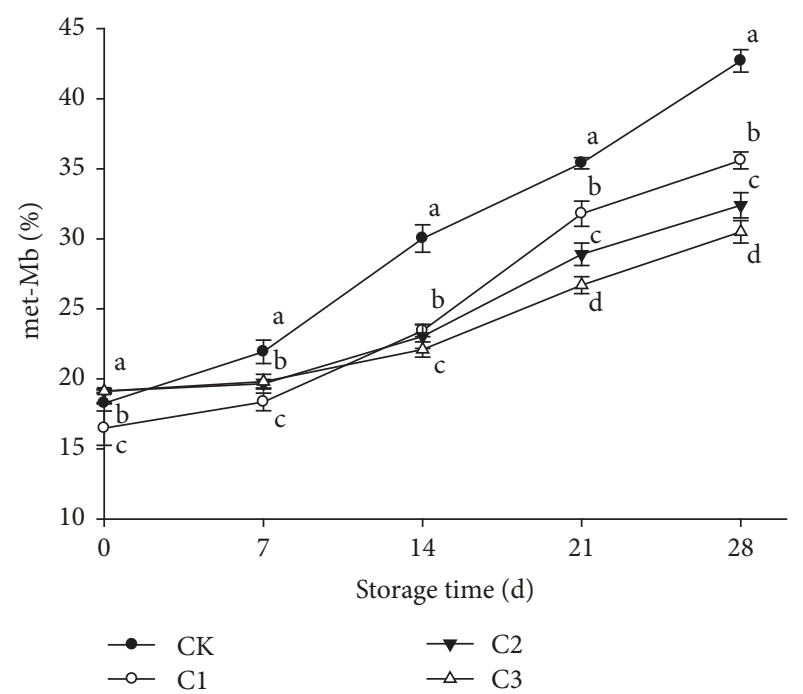

FIGURE 5: Changes in met-Mb content of beefsteaks with different treatments during storage. CK, the group of beefsteaks without pretreatments; $\mathrm{Cl}$, the group of beefsteaks pretreated with $100 \%$ CO for $1.5 \mathrm{~h}$; C2, group of beefsteaks pretreated with $100 \% \mathrm{CO}$ for $1.5 \mathrm{~h}$ and soaked in $50 \mathrm{mg} / \mathrm{L} \mathrm{ClO}_{2} ; \mathrm{C} 3$, group of beefsteaks pretreated with $100 \% \mathrm{CO}$ for $1.5 \mathrm{~h}$ and soaked in $50 \mathrm{mg} / \mathrm{L} \mathrm{ClO}_{2}$ for $10 \mathrm{~min}$ and sprayed with $30 \mathrm{~g} / \mathrm{L}$ lactic acid. Data were represented with mean values \pm Standard Error; sometimes the bars were too small to see. Different letters mean significant difference of samples with different treatments on the same storage days $(P<0.05)$. Three separate steaks of each treatment were measured; three repetitions were performed for each treatment. $n=9$.

within the spoiled limit level. C3 showed the best effect on maintaining low TVB-N, followed by $\mathrm{C} 2$ and $\mathrm{C} 1$.

TVB-N is the most important spoilage indicator in different types of meat as nitrogenous compounds are formed due to the decomposition resulting from the decarboxylation and deamination caused by the growth of microorganisms [41]. Balamatsia et al. [42] have demonstrated that the growth of Pseudomonas spp. and Enterobacteriaceae could explain the TVB-N changes of meat during storage. Olafsdottir et al. [43] also observed the good correlation between the populations of spoilage microorganisms and TVB-N values. Recently, the increase of TVB-N could be attributed to the rising counts of microorganisms. The lower values of TVB-N with C3 than other treatments could be related to the inhibition of growth of microorganisms, which is similar to the changes of TVC.

3.5. Metmyoglobin Analysis. Changes in met-Mb of beefsteaks are shown in Figure 5. Contents of met-Mb of all samples with or without treatments significantly increased during storage. Met-Mb contents of $\mathrm{CK}$ increased progressively during 28 days of storage, followed by $\mathrm{C} 1, \mathrm{C} 2$, and $\mathrm{C} 3(P<$ 0.05). Beefsteaks in treatments had lower met-Mb contents than control group at the end of storage, where C3 had the lowest one. Mancini and Ramanathan [44] demonstrated that met-Mb formation in beef was robustly reduced by lactic acid-enhancement, suggesting that lactic acid may be directly 


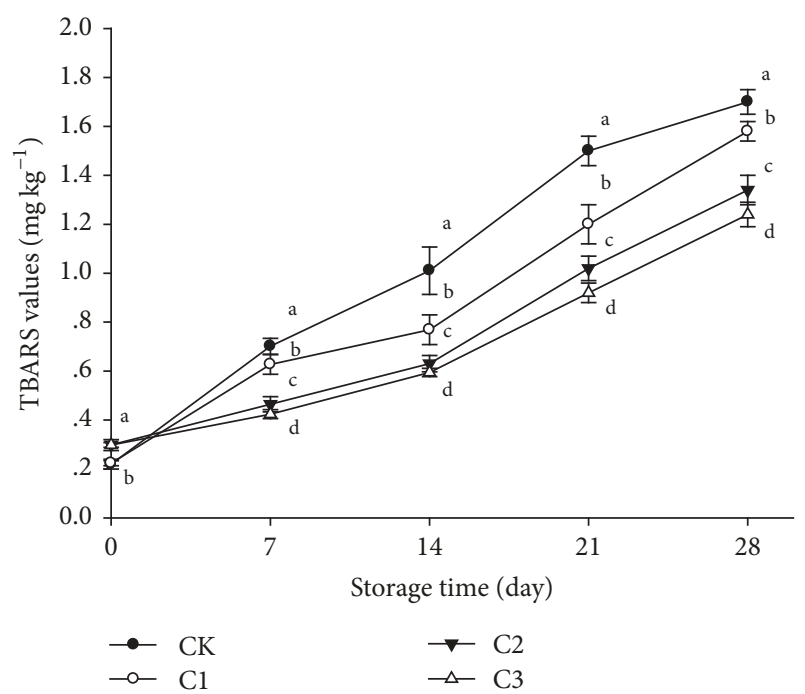

FIGURE 6: Changes in TBARS of beefsteaks with different treatments during storage. $\mathrm{CK}$, the group of beefsteaks without pretreatments; $\mathrm{C} 1$, the group of beefsteaks pretreated with $100 \%$ CO for $1.5 \mathrm{~h} ; \mathrm{C} 2$, group of beefsteaks pretreated with $100 \% \mathrm{CO}$ for $1.5 \mathrm{~h}$ and soaked in $50 \mathrm{mg} / \mathrm{L} \mathrm{ClO}_{2}$; C3, group of beefsteaks pretreated with $100 \% \mathrm{CO}$ for $1.5 \mathrm{~h}$ and soaked in $50 \mathrm{mg} / \mathrm{L} \mathrm{ClO}_{2}$ for $10 \mathrm{~min}$ and sprayed with $30 \mathrm{~g} / \mathrm{L}$ lactic acid. Data were represented with mean values \pm Standard Error; sometimes the bars were too small to see. Different letters mean significant difference of samples with different treatments on the same storage days $(P<0.05)$. Three separate steaks of each treatment were measured; three repetitions were performed for each treatment. $n=9$.

involved in myoglobin redox stability. The results conformed to $a^{*}$ value in Figure 1 .

The meat surface that has been affected by $20 \%$ of met$\mathrm{Mb}$ can affect the purchase decisions of consumers and discrimination may occur [45]. Meat with met-Mb levels above $40 \%$ can lead to purchase rejection at point of sale [46]. According to Figure 4 , at the end of storage, the met-Mb of CK had beyond $40 \%$, so it will not have any commercial value. However, other treatments were not beyond the limit and have a longer shelf life. There was also a phenomenon in all CO pretreated treatments, where met-Mb values increased slightly at the beginning of the storage period and then increased rapidly until the end of storage. It may be because the binding capacity of $\mathrm{CO}$ to $\mathrm{Mb}$ became weak at the medium and later storage, due to the increasing degeneration of protein [47].

3.6. TBARS Analysis. Meat is susceptible to lipid oxidation due to the reaction of oxygen with unsaturated fats to form lipid peroxides and as a result off-flavor, rancidity, and surface discoloration occur. TBARS is used as an index of lipid oxidation. As seen in Figure 6 initial TBARS of C2 and C3 were higher than $\mathrm{CK}$ and $\mathrm{Cl}$ on day $0(P<0.05)$. It might be caused by $\mathrm{ClO}_{2}$, which could oxidize the lipid in beef. With the increasing days of storage the TBARS values of the meat increased, indicating that lipid oxidation increased in beefs during storage. The TBARS changes of C3 and C2 treatments were similar and their TBARS were lower than C1 and $\mathrm{CK}$, and the differences became more significant after 7 days $(P<0.05)$. At the end of storage period, $\mathrm{C} 3$ had lowest TBARS $(P<0.05)$, followed by $\mathrm{C} 2, \mathrm{Cl}$, and CK $(P<0.05)$. The results suggested that $\mathrm{CO}$ pretreatment combined with $\mathrm{ClO}_{2}$ and lactic acid can delay the lipid oxidation of beef at whole storage period. It is might due to the inactivation activity of $\mathrm{ClO}_{2}$ and lactic acid for microorganisms, which might reduce the lipid oxidation. Similar results were also reported in literatures [48-50].

3.7. Fatty Acid Profile Analysis. Results attributed to the main fatty acids of different treatments and their important ratios in the three formulations of beef were given in Table 1. The percentage of saturated fatty acid (SFA), polyunsaturated fatty acids (PUFAs), and monounsaturated fatty acids (MUFAs) on day 0 were $32.18,10.56$, and $55.02 \%$, respectively. The most predominant fatty acids were palmitic acid, hexadecenoic acid, stearic acid, oleic acid, linoleic acid, and arachidonic acid. A similar proportion of fatty acids in beefsteaks were reported in literature [51]. During storage, the levels of SFA increased in all beefs, while MUFA and PUFA decreased. The amount of UFA that gradually decreased during storage was a likely consequence of the development of oxidative reactions. MUFAs are more susceptible to lipid oxidation because hydrogen atoms can be more easily abstracted from polyunsaturated fats than saturated fats [52].

SFAs of CK, C1, C2, and C3 were 53.88, 46.44, 52.11, and $41.74 \%$, respectively, at the end of storage. In comparison with the control beef, the beef treated with $\mathrm{CO}$ pretreatment, especially the pretreatment of $\mathrm{CO}$ combined with lactic acid and $\mathrm{ClO}_{2}$, had the lowest SFAs. While the proportions of MUFA and PUFA of C3 were the highest. C2 had lower percentages of MUFA and PUFA than C1. It indicated that although the oxidation activity of $\mathrm{ClO}_{2}$ easily makes unsaturated fatty acids oxidize, the application of lactic acid could inhibit the oxidation and keep the UFA in a high level in beef.

\section{Conclusion}

In order to inhibit the microbial growth and maintain color stability of vacuum-packaged beef, $\mathrm{CO}$ pretreatment combined with $\mathrm{ClO}_{2}$ and lactic acid used in beef was studied. The results indicated that $100 \%$ CO pretreatment combined with $50 \mathrm{mg} / \mathrm{L} \mathrm{ClO}_{2}$ and $30 \mathrm{~g} / \mathrm{L}$ lactic acid has the best effect of increasing the shelf life of beef by significantly inhibiting the bacterial growth, reducing the degree of chemical spoilage, and keeping high unsaturated fatty acid level, as well as retaining desirable color for beef. Color difference between beef samples treated by $\mathrm{ClO}_{2}$ and lactic acid was lower than other untreated samples, indicating that lactic acid did not have negative effect on the color of $\mathrm{CO}$ pretreated beef. This study confirmed that the potential utility of lactic acid and $\mathrm{ClO}_{2}$ was an effective way to extend shelf life of $\mathrm{CO}$ pretreated beef products and maintain the redness of beef for longer time. 
TABLE 1: Effect of different treatments on fatty acid profile (\% of total fatty acids) of the beefsteaks.

\begin{tabular}{|c|c|c|c|c|c|c|c|c|c|}
\hline \multirow{2}{*}{$\begin{array}{l}\text { Fatty } \\
\text { acids }\end{array}$} & \multirow[t]{2}{*}{$d$} & \multicolumn{2}{|c|}{ CK } & \multicolumn{2}{|c|}{$\mathrm{C} 1$} & \multicolumn{2}{|c|}{$\mathrm{C} 2$} & \multicolumn{2}{|c|}{$\mathrm{C} 3$} \\
\hline & & $14 \mathrm{~d}$ & $28 \mathrm{~d}$ & $14 \mathrm{~d}$ & $28 \mathrm{~d}$ & $14 \mathrm{~d}$ & $28 \mathrm{~d}$ & $14 \mathrm{~d}$ & $28 \mathrm{~d}$ \\
\hline $\mathrm{C} 12: 0$ & $0.06 \pm 0.01$ & $0.08 \pm 0.01$ & $12 \pm 0.01$ & $0.08 \pm 0.01$ & $0.13 \pm 0.04$ & $0.14 \pm 0.02$ & $0.3 \pm 0.01$ & $0.09 \pm 0.01$ & $0.13 \pm 0.01$ \\
\hline C14:0 & $2.01 \pm 0.03$ & $3.32 \pm 0.52$ & $4.46 \pm 1.05$ & $2.21 \pm 0.46$ & $2.49 \pm 0.68$ & $3.13 \pm 0.32$ & $4.22 \pm 0.74$ & $2.09 \pm 0.09$ & $2.13 \pm 0.42$ \\
\hline C14:1 & $1.46 \pm 0.08$ & $0.86 \pm 0.05$ & $0.69 \pm 0.04$ & $0.78 \pm 0.10$ & $0.58 \pm 0.04$ & $1.11 \pm 0.08$ & $0.94 \pm 0.07$ & $0.79 \pm 0.09$ & $0.61 \pm 0.06$ \\
\hline $\mathrm{C} 15: 0$ & $0.76 \pm 0.01$ & $0.91 \pm 0.05$ & $02+018$ & $0.77 \pm 0.02$ & $0.78 \pm 0.07$ & $0.84 \pm 0.06$ & $2+005$ & $0.74 \pm 0.12$ & $0.72 \pm 0.08$ \\
\hline $\mathrm{C} 15: 1$ & $51 \pm 0.01$ & $0.43 \pm 0.02$ & $.36 \pm 0.04$ & $0.36 \pm 0.01$ & $0.22 \pm 0$ & $0.39 \pm 0.01$ & $6 \pm 0.07$ & $0.36 \pm 0.03$ & $0.24 \pm 0.01$ \\
\hline $\mathrm{C} 16: 0$ & $17.37 \pm 2.14$ & $23.31 \pm 3.06$ & $26.47 \pm 2.07$ & $23.71 \pm 1.97$ & $26.26 \pm 0.98$ & $24.49 \pm 2.87$ & $28.88 \pm 1.22$ & $23.88 \pm 2.11$ & $26.4 \pm 1.67$ \\
\hline $\mathrm{C} 16: 1$ & $5.02 \pm 0.42$ & $3.57 \pm 0.42$ & $2.64 \pm 0.42$ & $62 \pm 0.61$ & $2.62 \pm 0.42$ & $3.74 \pm 0.57$ & $3.09 \pm 0.81$ & $4.87 \pm 0.50$ & $4.72 \pm 0.63$ \\
\hline C17:0 & $1.79 \pm 0.05$ & $1.31 \pm 0.08$ & $.79 \pm 0.09$ & $.25 \pm 0.06$ & $0.59 \pm 0.10$ & $1.32 \pm 0.05$ & $0.78 \pm 0.11$ & $1.26 \pm 0.04$ & $0.62 \pm 0.08$ \\
\hline $\mathrm{C} 17: 1$ & $5.02 \pm 0.11$ & $2.25 \pm 0.07$ & $1.9 \pm 0.03$ & $2.8 \pm 0.06$ & $2.64 \pm 0.11$ & $2.25 \pm 0.12$ & $1.89 \pm 0.07$ & $2.43 \pm 0.04$ & $2 \pm 0.08$ \\
\hline C18:0 & $10.01 \pm 1$ & $15.71 \pm 1.01$ & & & & & & & \\
\hline $\begin{array}{l}\text { C18:1, } \\
\text { c9 }(n-9)\end{array}$ & $43.01 \pm 3.68$ & $36.11 \pm 4.02$ & $32.82 \pm 3.67$ & $37.41 \pm 3.69$ & $35.72 \pm 3.94$ & $36.38 \pm 3.98$ & $32.73 \pm 3.62$ & $39.63 \pm 4.25$ & $39.51 \pm 4.18$ \\
\hline $\begin{array}{l}\mathrm{C} 18: 2 \\
\mathrm{t} 6\end{array}$ & $3.59 \pm 0.57$ & $2.59 \pm 0.42$ & $1.34 \pm 0.51$ & $2.47 \pm 0.26$ & $1.42 \pm 0.26$ & $2.51 \pm 0.33$ & $1.9 \pm 0.11$ & $3 \pm 0.71$ & $2.55 \pm 0.39$ \\
\hline $\begin{array}{l}\text { C18:2, } \\
\text { c6 }(n-6)\end{array}$ & $0.29 \pm 0.03$ & $0.41 \pm 0.02$ & $0.53 \pm 0.11$ & $0.27 \pm 0.07$ & $0.26 \pm 0.12$ & $0.38 \pm 0.06$ & $0.45 \pm 0.05$ & $0.28 \pm 0.08$ & $0.31 \pm 0.03$ \\
\hline $\begin{array}{l}\mathrm{C} 18: 3 \\
(n-3)\end{array}$ & $4.12 \pm 0.59$ & $2.77 \pm 1.42$ & $1.45 \pm 0.96$ & $3.49 \pm 1.06$ & $3.19 \pm 1.09$ & $3.13 \pm 0.88$ & $1.4 \pm 0.84$ & $3.79 \pm 1.18$ & $3.59 \pm 0.79$ \\
\hline C20:0 & $0.18 \pm 0.02$ & $0.27 \pm 0.08$ & $.32 \pm 0.02$ & $0.46 \pm 0.05$ & $0.76 \pm 0.06$ & & $0.45 \pm 0.05$ & $0.22 \pm 0.02$ & $0.28 \pm 0.03$ \\
\hline $\begin{array}{l}C 20: 4 \\
(n-6)\end{array}$ & $2.02 \pm 0.21$ & $0.83 \pm 0.04$ & $0.6 \pm 0.04$ & $1.56 \pm 0.12$ & $1.56 \pm 0.16$ & $0.71 \pm 0.06$ & $0.4 \pm 0.02$ & $1.24 \pm 0.17$ & $1.19 \pm 0.09$ \\
\hline $\begin{array}{l}\text { C20:5 } \\
(n-3)\end{array}$ & $0.54 \pm 0.03$ & $0.32 \pm 0.03$ & $0.17 \pm 0.01$ & $0.34 \pm 0.05$ & $0.25 \pm 0.02$ & $0.3 \pm 0.02$ & $0.21 \pm 0.03$ & $0.41 \pm 0.02$ & $0.35 \pm 0.03$ \\
\hline SFA & $32.18 \pm 3.13$ & $44.91 \pm 4.98$ & $53.88 \pm 4.08$ & $42.37 \pm 4.73$ & $46.44 \pm 4.09$ & $44.36 \pm 5.02$ & $52.11 \pm 4.11$ & $40.06 \pm 5.17$ & $41.74 \pm 4.81$ \\
\hline MUFA & $55.02 \pm 5.31$ & $43.22 \pm 5.08$ & $38.41 \pm 3.92$ & $44.13 \pm 4.21$ & $41.77 \pm 4.72$ & $43.87 \pm 4.02$ & $39.02 \pm 4.34$ & $48.08 \pm 5.01$ & $46.26 \pm 4.22$ \\
\hline PUFA & $10.56 \pm 1.51$ & $6.92 \pm 2.01$ & $4.09 \pm 1.51$ & $8.13 \pm 1.96$ & $6.68 \pm 1.82$ & $7.03 \pm 2.54$ & $4.36 \pm 2.09$ & $8.72 \pm 2.15$ & $8 \pm 2.03$ \\
\hline
\end{tabular}

$\mathrm{CK}$, the group of beefsteaks without pretreatments; $\mathrm{C} 1$, the group of beefsteaks pretreated with $100 \% \mathrm{CO}$ for $1.5 \mathrm{~h}$; $\mathrm{C} 2$, group of beefsteaks pretreated with $100 \% \mathrm{CO}$ for $1.5 \mathrm{~h}$ and soaked in $50 \mathrm{mg} / \mathrm{L} \mathrm{ClO}{ }_{2}$; C3, group of beefsteaks pretreated with $100 \%$ for $\mathrm{CO} 1.5 \mathrm{~h}$ and soaked in $50 \mathrm{mg} / \mathrm{L} \mathrm{ClO} 2$ for $10 \mathrm{~min}$ and sprayed with $30 \mathrm{~g} / \mathrm{L}$ lactic acid. Data were represented with mean values \pm Standard Error. SFA, saturated fatty acid; MUFA, monounsaturated fatty acid; PUFA, polyunsaturated fatty acid.

\section{Conflicts of Interest}

The authors declare that there are no conflicts of interest.

\section{Acknowledgments}

This work was supported by the Major Science and Technology Projects of Zhejiang Province (Grant no. 2015C02038) and China Postdoctoral Science Foundation (Grant no. 2016M601968).

\section{References}

[1] M. Renerre, "Factors involved in the discoloration of beef meat," International Journal of Food Science \& Technology, vol. 25, no. 6, pp. 613-630, 1990.

[2] M. R. Stivarius, F. W. Pohlman, K. S. McElyea, and J. K. Apple, "Microbial, instrumental color and sensory color and odor characteristics of ground beef produced from beef trimmings treated with ozone or chlorine dioxide," Meat Science, vol. 60, no. 3, pp. 299-305, 2002.
[3] W. N. SAWAYA, A. S. ELNAWAWY, S. AL-ZENKI, J. AL-OTAIBI, H. AL-OMIRAH, and H. AL-AMIRI, "Storage Stability of Chicken as Affected by Map and Lactic Acid Treatment," Journal of Food Science, vol. 60, no. 3, pp. 611-614, 1995.

[4] C. Rodríguez-Melcón, C. Alonso-Calleja, and R. Capita, "Lactic acid concentrations that reduce microbial load yet minimally impact colour and sensory characteristics of beef," Meat Science, vol. 129, pp. 169-175, 2017.

[5] D. Duan, H. Wang, S. Xue, M. Li, and X. Xu, "Application of disinfectant sprays after chilling to reduce the initial microbial load and extend the shelf-life of chilled chicken carcasses," Food Control, vol. 75, pp. 70-77, 2017.

[6] N. Smigic, A. Rajkovic, D. S. Nielsen, N. Arneborg, H. Siegumfeldt, and F. Devlieghere, "Survival of lactic acid and chlorine dioxide treated Campylobacter jejuni under suboptimal conditions of $\mathrm{pH}$, temperature and modified atmosphere," International Journal of Food Microbiology, vol. 141, pp. S140S146, 2010

[7] J. R. UNDA, R. A. MOLINS, and C. A. ZAMOJCIN, "Sanitization of Fresh Rib Eye Steaks with Chlorine Dioxide-Generating 
Binary Systems," Journal of Food Science, vol. 54, no. 1, pp. 7-10, 1989.

[8] M. G. O'Sullivan and J. P. Kerry, "Sensory and quality properties of packaged fresh and processed meats," Advances in Meat, Poultry and Seafood Packaging, pp. 86-111, 2012.

[9] R. A. Mancini and M. C. Hunt, "Current research in meat color," Meat Science, vol. 71, no. 1, pp. 100-121, 2005.

[10] O. Sørheim, T. Aune, and T. Nesbakken, "Technological, hygienic and toxicological aspects of carbon monoxide used in modified-atmosphere packaging of meat," Trends in Food Science \& Technology, vol. 8, no. 9, pp. 307-312, 1997.

[11] B. H. P. Wilkinson, J. A. M. Janz, P. C. H. Morel, R. W. Purchas, and W. H. Hendriks, "The effect of modified atmosphere packaging with carbon monoxide on the storage quality of master-packaged fresh pork," Meat Science, vol. 73, no. 4, pp. 605-610, 2006.

[12] F. Lyu, K. Shen, Y. Ding, and X. Ma, "Effect of pretreatment with carbon monoxide and ozone on the quality of vacuum packaged beef meats," Meat Science, vol. 117, pp. 137-146, 2016.

[13] L. Martínez, D. Djenane, I. Cilla, J. A. Beltrán, and P. Roncalés, "Effect of different concentrations of carbon dioxide and low concentration of carbon monoxide on the shelf-life of fresh pork sausages packaged in modified atmosphere," Meat Science, vol. 71, no. 3, pp. 563-570, 2005.

[14] J. Y. Jeong and J. R. Claus, "Color stability and reversion in carbon monoxide packaged ground beef,' Meat Science, vol. 85, no. 3, pp. 525-530, 2010.

[15] M. C. Hunt, R. A. Mancini, K. A. Hachmeister et al., "Carbon Monoxide in Modified Atmosphere Packaging Affects Color, Shelf Life, and Microorganisms of Beef Steaks and Ground Beef," Journal of Food Science, vol. 69, no. 1, pp. FCT45-FCT52, 2004.

[16] L. A. Van Rooyen, P. Allen, S. M. Crawley, and D. I. O'Connor, "The effect of carbon monoxide pretreatment exposure time on the colour stability and quality attributes of vacuum packaged beef steaks," Meat Science, vol. 129, pp. 74-80, 2017.

[17] D. Guggisberg and J. Bosset, "Colour in food (Improving quality)," LWT- Food Science and Technology, vol. 36, no. 3, pp. 375-376, 2003.

[18] M. R. STEWART, M. W. ZIPSER, and B. M. WATTS, “The Use of Reflectance Spectrophotometry for the Assay of Raw Meat Pigments," Journal of Food Science, vol. 30, no. 3, pp. 464-469, 1965.

[19] P. D. Warriss, "Adrenal ascorbic acid depletion as an index of preslaughter stress in pigs," Meat Science, vol. 3, no. 4, pp. 281$285,1979$.

[20] G. R. TROUT, "Variation in Myoglobin Denaturation and Color of Cooked Beef, Pork, and Turkey Meat as Influenced by $\mathrm{pH}$, Sodium Chloride, Sodium Tripolyphosphate, and Cooking Temperature," Journal of Food Science, vol. 54, no. 3, pp. 536540, 1989.

[21] K. Krzywicki, "Assessment of relative content of myoglobin, oxymyoglobin and metmyoglobin at the surface of beef," Meat Science, vol. 3, no. 1, pp. 1-10, 1979.

[22] L. D. Luqué, B. J. Johnson, J. N. Martin et al., "Zilpaterol hydrochloride supplementation has no effect on the shelf life of ground beef," Journal of Animal Science, vol. 89, no. 3, pp. 817$825,2011$.

[23] L. John, D. Cornforth, C. E. Carpenter, O. Sorheim, B. C. Pettee, and D. R. Whittier, "Color and thiobarbituric acid values of cooked top sirloin steaks packaged in modified atmospheres of $80 \%$ oxygen, or $0.4 \%$ carbon monoxide, or vacuum," Meat Science, vol. 69, no. 3, pp. 441-449, 2005.

[24] B. Wang, R. D. Pace, A. P. Dessai, A. Bovell-Benjamin, and B. Phillips, "Modified extraction method for determining 2thiobarbituric acid values in meat with increased specificity and simplicity," Journal of Food Science, vol. 67, no. 8, pp. 2833-2836, 2002.

[25] R. Sinnhuber and T. Yu, "Characterization of the red pigment formed in 2-thiobarbituric acid determination of oxidative rancidity," Journal of Food Science, vol. 23, no. 6, pp. 626-634, 1958.

[26] J. Folch, M. Lees, and G. H. Sloane Stanley, "A simple method for the isolation and purification of total lipides from animal tissues," The Journal of Biological Chemistry, vol. 226, no. 1, pp. 497-509, 1957.

[27] W. R. Morrison and L. M. Smith, "Preparation of fatty acids methyl esters and dimethylacetals," Journal of Lipid Research, vol. 5, pp. 600-608, 1964.

[28] P. Pipek, M. Šikulová, J. Jeleniíková, and M. Izumimoto, “Colour changes after carcasses decontamination by steam and lactic acid," Meat Science, vol. 69, no. 4, pp. 673-680, 2005.

[29] C. Han, J. Wang, Y. Li, F. Lu, and Y. Cui, "Antimicrobial-coated polypropylene films with polyvinyl alcohol in packaging of fresh beef," Meat Science, vol. 96, no. 1, pp. 901-907, 2014.

[30] G. H. Zhou, X. L. Xu, and Y. Liu, "Preservation technologies for fresh meat-a review," Meat Science, vol. 86, no. 1, pp. 119-128, 2010.

[31] H. Kim, Y. Kang, L. R. Beuchat, and J.-H. Ryu, "Production and stability of chlorine dioxide in organic acid solutions as affected by $\mathrm{pH}$, type of acid, and concentration of sodium chlorite, and its effectiveness in inactivating Bacillus cereus spores," Food Microbiology, vol. 25, no. 8, pp. 964-969, 2008.

[32] K. Harris, M. F. Miller, G. H. Loneragan, and M. M. Brashears, "Validation of the use of organic acids and acidified sodium chlorite to reduce Escherichia coli O157 and Salmonella typhimurium in beef trim and ground beef in a simulated processing environment," Journal of Food Protection, vol. 69, no. 8, pp. 1802-1807, 2006.

[33] F. De Santos, M. Rojas, G. Lockhorn, and M. S. Brewer, "Effect of carbon monoxide in modified atmosphere packaging, storage time and endpoint cooking temperature on the internal color of enhanced pork," Meat Science, vol. 77, no. 4, pp. 520-528, 2007.

[34] P. I. Zakrys, S. A. Hogan, M. G. O'Sullivan, P. Allen, and J. P. Kerry, "Effects of oxygen concentration on the sensory evaluation and quality indicators of beef muscle packed under modified atmosphere," Meat Science, vol. 79, no. 4, pp. 648-655, 2008.

[35] B. A. Behbahani, F. Shahidi, F. T. Yazdi, S. A. Mortazavi, and M. Mohebbi, "Use of Plantago major seed mucilage as a novel edible coating incorporated with Anethum graveolens essential oil on shelf life extension of beef in refrigerated storage," International Journal of Biological Macromolecules, vol. 94, pp. 515-526, 2017.

[36] J. M. Lorenzo, R. Batlle, and M. Gómez, "Extension of the shelflife of foal meat with two antioxidant active packaging systems," LWT-Food Science and Technology, vol. 59, no. 1, pp. 181-188, 2014.

[37] J. B. M. Rodrigues, C. I. G. L. Sarantópoulos, R. Bromberg et al., "Evaluation of the effectiveness of non-irradiated and chlorinefree packaging for fresh beef preservation," Meat Science, vol. 125 , pp. 30-36, 2017. 
[38] N. Lavieri and S. K. Williams, "Effects of packaging systems and fat concentrations on microbiology, sensory and physical properties of ground beef stored at $4 \pm 1 \circ \mathrm{C}$ for 25 days," Meat Science, vol. 97, no. 4, pp. 534-541, 2014.

[39] B. M. Naveena, M. Muthukumar, A. R. Sen, Y. Babji, and T. R. K. Murthy, "Improvement of shelf-life of buffalo meat using lactic acid, clove oil and vitamin C during retail display," Meat Science, vol. 74, no. 2, pp. 409-415, 2006.

[40] T. Guo, M. Huang, Q. Zhu, Y. Guo, and J. Qin, "Hyperspectral image-based multi-feature integration for TVB-N measurement in pork," Journal of Food Engineering, vol. 218, pp. 61-68, 2018.

[41] F. Ghollasi-Mood, M. Mohsenzadeh, M.-R. Hoseindokht, and M. Varidi, "Quality changes of air-packaged chicken meat stored under different temperature conditions and mathematical modelling for predicting the microbial growth and shelf life," Journal of Food Safety, vol. 37, no. 3, Article ID e12331, 2017.

[42] C. C. Balamatsia, A. Patsias, M. G. Kontominas, and I. N. Savvaidis, "Possible role of volatile amines as quality-indicating metabolites in modified atmosphere-packaged chicken fillets: Correlation with microbiological and sensory attributes," Food Chemistry, vol. 104, no. 4, pp. 1622-1628, 2007.

[43] G. Olafsdottir, E. Martinsdóttir, J. Oehlenschläger, and etal., "Methods to evaluate fish freshness in research and industry," Trends in Food Science \& Technology, vol. 8, no. 8, pp. 258-265, 1997.

[44] R. A. Mancini and R. Ramanathan, "Sodium lactate influences myoglobin redox stability in vitro," Meat Science, vol. 78, no. 4, pp. 529-532, 2008.

[45] D. B. MacDougall, "Changes in the colour and opacity of meat," Food Chemistry, vol. 9, no. 1-2, pp. 75-88, 1982.

[46] B. E. Greene, I. Hsin, and M. Y. W. Zipser, "Retardation of oxidative color changes in raw ground beef," Journal of Food Science, vol. 36, no. 6, pp. 940-942, 1971.

[47] G. Smulevich, E. Droghetti, C. Focardi, M. Coletta, C. Ciaccio, and M. Nocentini, "A rapid spectroscopic method to detect the fraudulent treatment of tuna fish with carbon monoxide," Food Chemistry, vol. 101, no. 3, pp. 1071-1077, 2006.

[48] Z. Pietrasik, N. J. Gaudette, and M. Klassen, "Effect of hot water treatment of beef trimmings on processing characteristics and eating quality of ground beef," Meat Science, vol. 113, pp. 41-50, 2016.

[49] J. N. Martin, J. C. Brooks, T. A. Brooks et al., "Storage length, storage temperature, and lean formulation influence the shelflife and stability of traditionally packaged ground beef," Meat Science, vol. 95, no. 3, pp. 495-502, 2013.

[50] J. Łopacka, A. Półtorak, and A. Wierzbicka, "Effect of MAP, vacuum skin-pack and combined packaging methods on physicochemical properties of beef steaks stored up to 12 days," Meat Science, vol. 119, pp. 147-153, 2016.

[51] C. R. Kerth, A. L. Harbison, S. B. Smith, and R. K. Miller, "Consumer sensory evaluation, fatty acid composition, and shelf-life of ground beef with subcutaneous fat trimmings from different carcass locations," Meat Science, vol. 104, pp. 30-36, 2015.

[52] G. R. Sampaio, T. Saldanha, R. A. M. Soares, and E. A. F. S. Torres, "Effect of natural antioxidant combinations on lipid oxidation in cooked chicken meat during refrigerated storage," Food Chemistry, vol. 135, no. 3, pp. 1383-1390, 2012. 


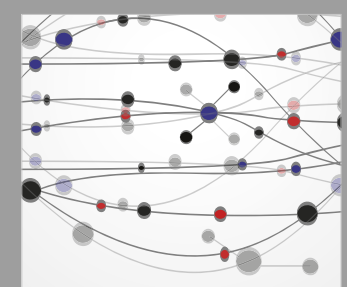

The Scientific World Journal
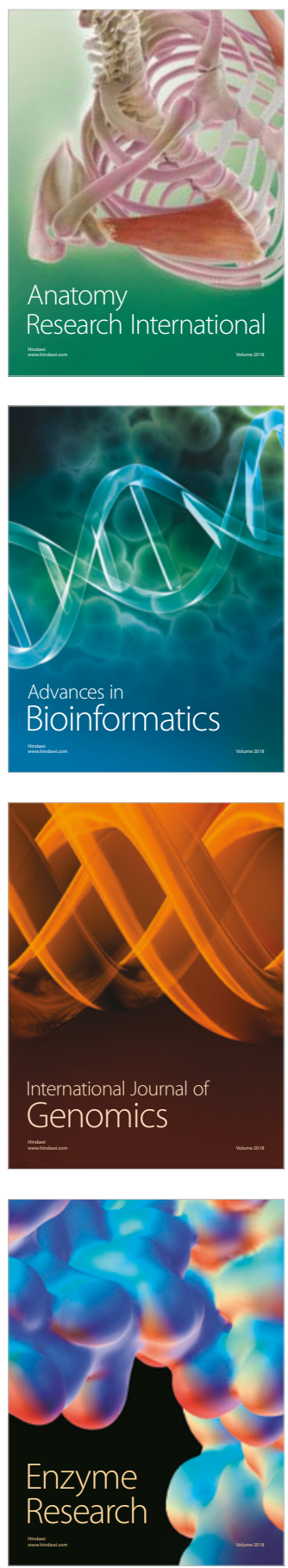
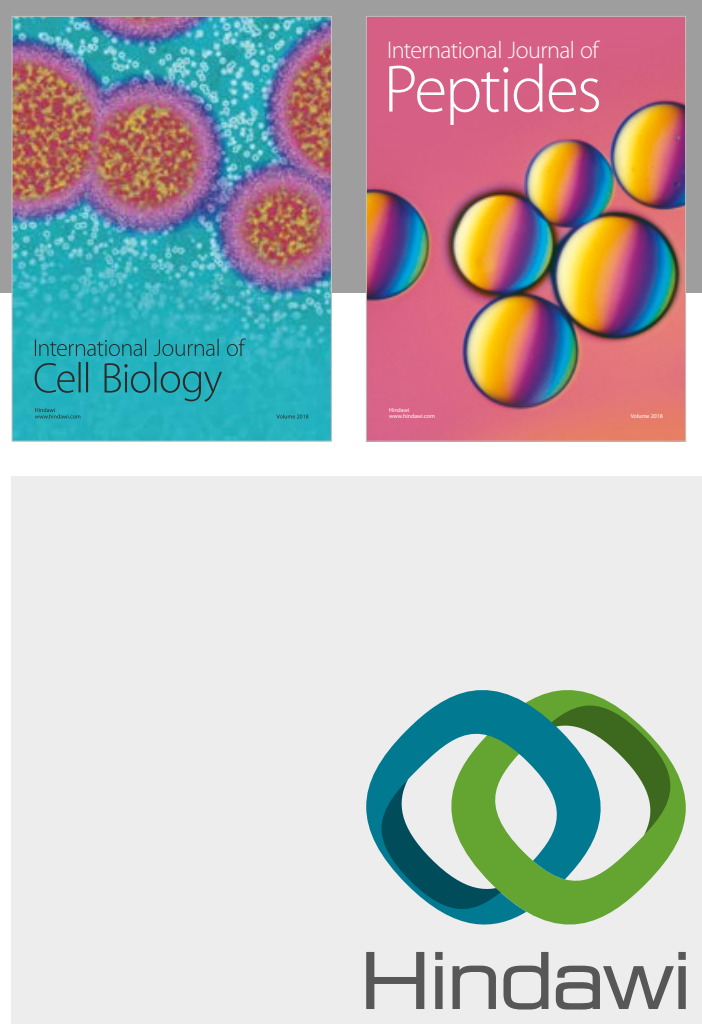

Submit your manuscripts at

www.hindawi.com
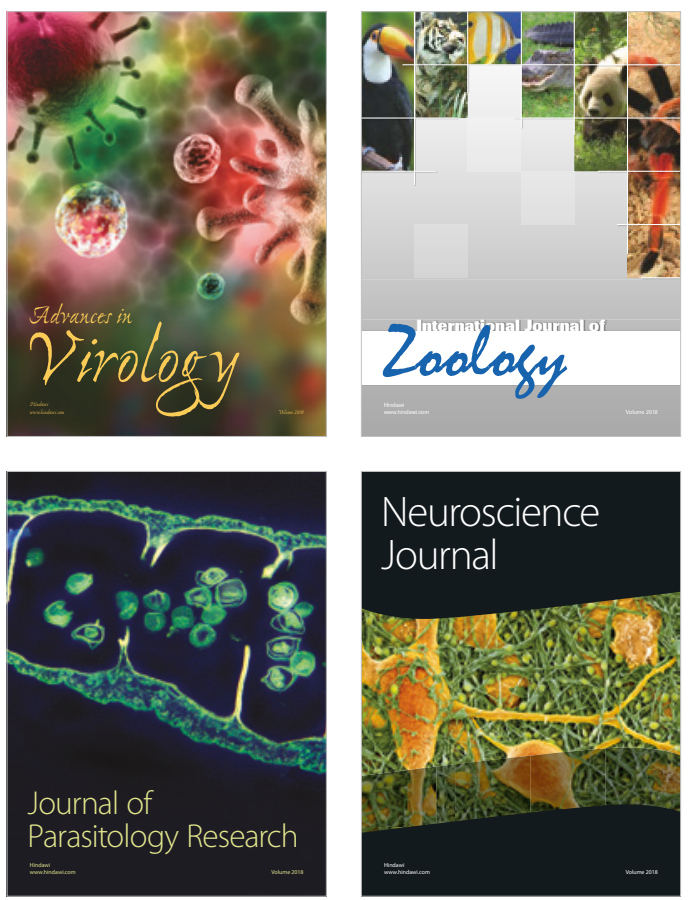
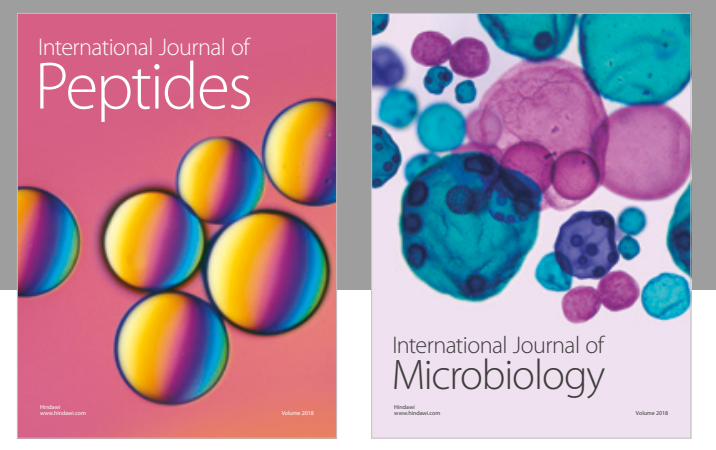

nternational Journal of Microbiology
Journal of
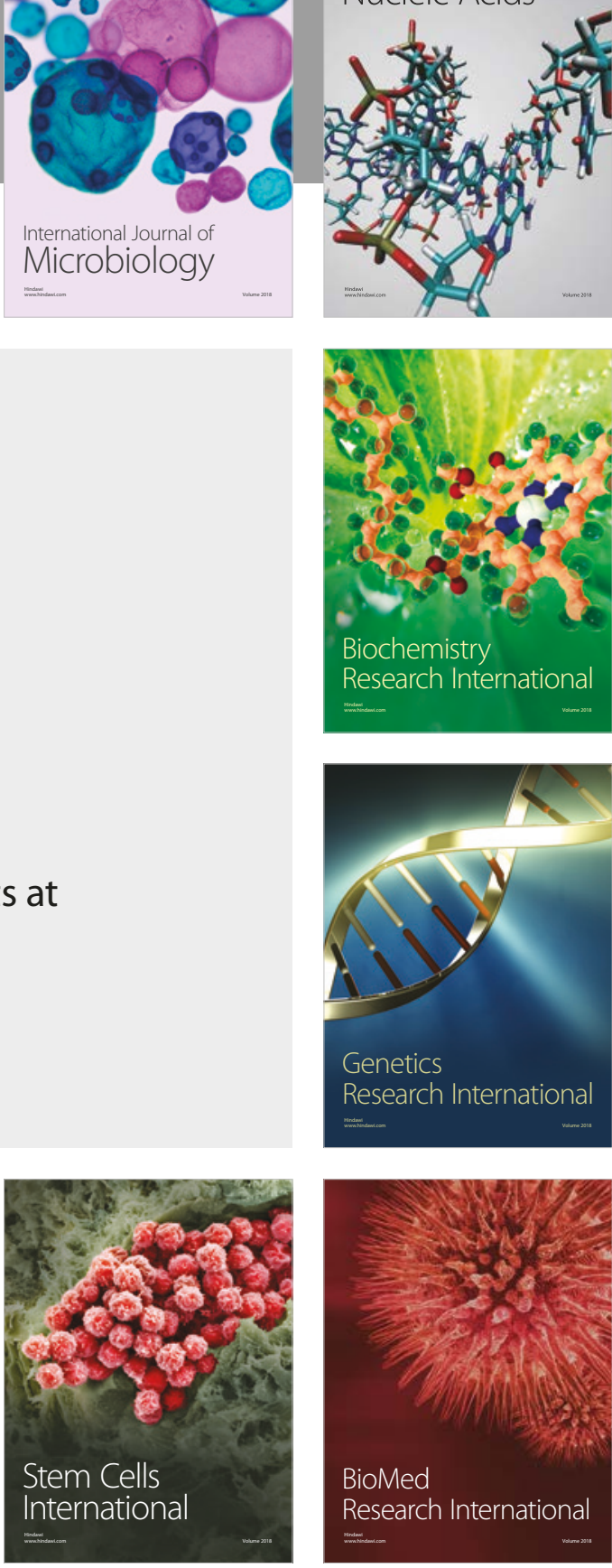
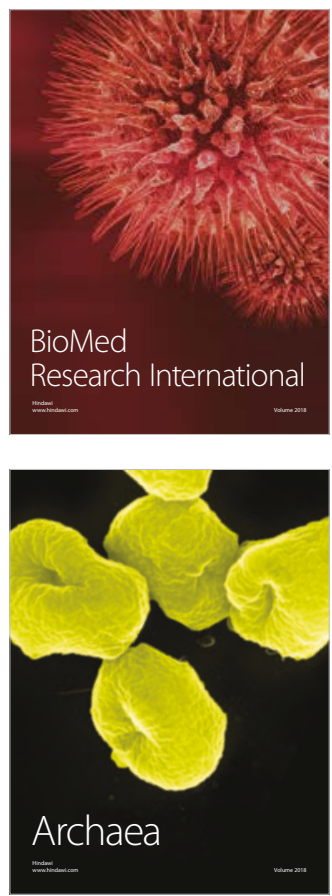